\title{
HEPATOPROTECTIVE EFFECT OF MATTHIOLA ARABICA BOISS Aganist CARBON TETRACHLORIDE INDUCED ACUTE LIVER INJURY
}

\author{
By \\ Eman D. Mohammed ${ }^{\mathrm{a}}$, Reem N. El-Naga ${ }^{\mathrm{b}}$, Rehab A. Lotfy ${ }^{\mathrm{a}}$, Ebtehal El-Demerdash $^{\mathrm{b}}$ \\ FROM \\ ${ }^{a}$ Natural Product Unit, Department of Medicinal and Aromatic Plants, Desert \\ Research Center, Cairo, Egypt \\ ${ }^{b}$ Department of Pharmacology and Toxicology, Faculty of Pharmacy, Ain Shams \\ University, Cairo, Egypt
}

\begin{abstract}
Chronic liver diseases one of the most common causes of death in the world due to different etiologies. Carbon tetrachloride $\left(\mathrm{CCl}_{4}\right)$ one of the well known toxicant used in most of acute and chronic liver injury. Therefore, several researches have been directed toward natural products to develop a new pharmacologically effective agents in the treatment of liver diseases. Matthila arabica Boiss. one of the brassicaceae's plants which is famous with the presence of pharmacologically active glucsinolates hydrolysis products (GLCsHPs). The present study was performed to investigate the hepatoprotective effect of (GLCsHPs) fraction of $M$. arabica against carbon tetrachloride $\left(\mathrm{CCl}_{4}\right)$ induced acute liver injury at a dose of $1 \mathrm{ml} / \mathrm{kg}$ injected intraperitoneally as a mixture with corn oil in the seventh day. The (GLCsHPs) fraction was administered in different three doses of $7.5,15$ and $30 \mathrm{mg} / \mathrm{kg}$ orally for six consecutive days followed by single dose of $\mathrm{CCl}_{4}$ at a dose of $1 \mathrm{ml} / \mathrm{kg}$ injected intraperitoneally as a mixture with corn oil in the seventh day. The hepatoprotective effect was assessed via liver function tests and histopathological liver sections. Significant reduction in the hepatic enzymes levels was found in animals treated with different doses of (GLCsHPs) fraction particularly at a dose of $30 \mathrm{mg} / \mathrm{kg}$ as well as restoration of hepatocellular architecture. These findings is indicative for the promising hepatoprotective effect of (GLCsHPs) fraction against $\mathrm{CCl}_{4}$-induced acute liver injury.
\end{abstract}

Keywords: Matthiola arabica ; GLCsHP; Carbon tetrachloride; Hepatoprotective; Rats.

\section{INTRODUCTION}

Due to the important vital functions of the liver in the body such as synthesis, storage, metabolism, and excretion (Martini et al., 2006). Besides, the detoxification of xenobiotics and endogenous compounds by converting them to less toxic, easy eliminated compounds by the kidney (Sargent, 2009). Chronic liver diseases have concerned one of the most important health problems in the world caused by many hepatotoxicants such as toxic chemicals, drugs, alcohol, and/or viral infection, which are characterized by a progressive evolution from steatosis to chronic hepatitis, fibrosis, cirrhosis, and hepatocellular carcinoma (Loguercio, and Federico, 2003). 
Carbon tetrachloride $\left(\mathrm{CCl}_{4}\right)$ considered as ordinary hepatotoxic agent which used in the most preclinical animal's studies, due to its ability to induce free radical mediating acute liver injury in rats (Matkowski, 2008). This liver injury leads to necrosis, steatosis, and foamy degeneration followed by the progression in to fibrosis (Recknagel et al., 1989). The metabolism of $\mathrm{CCl}_{4}$, catalyzed by liver microsomal cytochrome P450, rapidly overproduces free radicals that deplete hepatic glutathione (GSH) and initiates a chain lipid peroxidation of the hepatocyte membrane and results in oxidative stress and hepatocyte injuries. These pathological changes caused by $\mathrm{CCl}_{4}$ toxicity resemble the processes of chronic hepatitis and cirrhosis in human (Guicciardi, and Gores, 2005; Alqasoumi, 2010).

In the absence of an effective pharmacological therapy for such pathological processes, many researchers have directed toward herbal drugs or plant extracts for the treatment of liver diseases. Brassicaceae is one of the most important plant families due to its richness with glucosinolates, glucose and sulfur containing compounds, which are decomposed by the action of myrosinase enzyme into different pharmacogical important products, including substituted isothiocyanates, nitriles, thiocyanates, epithionitriles and oxazolidinethiones. (Gil and Macleod, 1980; Fenwick et al., 1983).

Several researches focused in glucosinolates hydrolysis products (GLCsHPs) due to their pharmacological activity such as biocidal (Vaughn, 1999) and cancer chemopreventive activities (Fahey et al., 2001). These activities encouraged us to investigate the hepatoprotective effect of Matthiola arabica Boiss., one of the Brassicaceae's plants which present in Egyptian desert (Boulos, 1999 and Täckholm, 1974), in a $\mathrm{CCl}_{4}$-induced acute hepatotoxicity model.

\section{MATERIALS AND METHODS}

\section{Plant material}

Matthiola arabica (Boiss.) aerial part was collected from Wadi-Gebal, Saint Catherin protectorate, south Sinai, Egypt in April 2015. It was identified by Dr. Atia Eisa, lecturer of Plant Taxonomy, Faculty of Science, Damanhour University, Egypt.Voucher sample was kept in the botanical Herbarium, Desert Research Center, Egypt.

The fraction rich in glucosinolates hydrolysis products of the aerial part of $M$. arabica (GLCsHPs) was prepared by natural autolysis method according to Al-Gendy and Lockwood (2003).

\section{Animals and experimental protocol}

The studies were conducted in accordance with ethical guidelines of Ain Shams University, Egypt. Male albino rats weighing 120-180 g rats were used in this study. They were supplied by Nile Co. for Pharmaceutical and Chemical industries, Egypt and housed in an air-conditioned atmosphere at $22 \pm 2^{\circ} \mathrm{C}$, under a $12 \mathrm{~h}$ light-dark cycle and provided with rodent chow and water ad libitum. Thirty animals were randomly divided into five different groups and treated for one week. Group 1: served as normal control received $1 \mathrm{ml} / \mathrm{kg}$ of corn oil injected interapretonially on the seventh day. Group 2: received $\mathrm{CCl}_{4}$ at a dose of $1 \mathrm{ml} / \mathrm{kg}$ (prepared as 1:1 mixture with corn oil) and injected 
interapretonially on the seventh day. Groups 3,4 and 5: received fraction rich in (GLCsHPs) at three different doses of $7.5,15$ and $30 \mathrm{mg} / \mathrm{kg}$ (prepared by natural autolysis method and given orally by gastric gavage) for six consecutive days followed by $\mathrm{CCl}_{4}$ as a single dose of $1 \mathrm{ml} / \mathrm{kg}$ (prepared as $1: 1$ mixture with corn oil) and injected interapretonially on the seven ${ }^{\text {th }}$ day. At the end of the week, the blood samples were collected from the retro-orbital plexus and allowed to clot. Serum was separated by centrifugation at $1000 \mathrm{~g}$ for $10 \mathrm{~min}$ and used for the assessment of liver functions. Then, rats were sacrificed and specimens from the three major lobes of each liver were fixed in $10 \%$ formalin for histopathological examination.

\section{Assessment of liver function tests}

The levels of ALT and AST were measured following the commercial kit's instructions (Spectrum diagnostics, Egypt).

\section{Histopathological examination}

For light microscopy, liver specimens were fixed in $10 \%$ formalin and embedded in paraffin. Sections of $4 \mu \mathrm{m}$ thickness were cut, stained with hematoxylin and eosin and subjected to photomicroscopic examination.

\section{Statistical analysis}

Data are presented as mean \pm standard deviation (SD). Statistical analysis was performed using one-way analysis of variance (ANOVA) followed by Tukey-Kramer as a post hoc test. The 0.05 level of probability was used as the criterion for significance. All statistical analyses were performed using Instat software package (version 3.06). The scores of histopathology were analyzed by non parametric methods using Kruskal Wallis followed by Dumr as a post hoc test.

\section{RESULTS}

\section{Effect of fraction rich in (GLCsHPs) on serum ALT and ASTactivities}

Serum ALT and AST levels were significantly increased in the $\mathrm{CCl}_{4}$-intoxicated group by 3.7 and 3.4 folds, respectively as compared to the control group, while pretreatment of animals with different doses of the (GLCsHPs) fraction showed a significant decrease in the serum ALT and AST levels as compared to the $\mathrm{CCl}_{4}$ group, in a dose dependent manner. Indeed, the highest dose $(30 \mathrm{mg} / \mathrm{kg}$ ) of the (GLCsHPs) fraction showed the highest hepatoprotection where it decreased ALT and AST serum levels by 60.8 and $51.5 \%$, respectively as compared to the $\mathrm{CCl}_{4}$.intoxicated group .But the low $(7.5 \mathrm{mg} / \mathrm{kg})$ and moderate $(15 \mathrm{mg} / \mathrm{kg})$ doses were induced low to moderate significant decrease in ALT and AST levels by 33.2 and $28.6 \%$, respectively of the low dose and 36.6 and $32.3 \%$, respectively of the moderate dose as compared to the $\mathrm{CCl}_{4}$ intoxicated group (Table 1). 
Table 1. Effects of different doses of (GLCsHPs) fraction $(7.5,15$ and $30 \mathrm{mg} / \mathrm{kg}$ given orally for six consecutive days) on serum ALT and AST levels in rats subjected to acute $\mathrm{CCl}_{4}$ intoxication

\begin{tabular}{|c|c|c|}
\hline Groups & ALT (U/L) & $\operatorname{AST}(\mathbf{U} / \mathrm{L})$ \\
\hline Control & $29.92 \pm 13.06^{b}$ & $87.6 \pm 18.43^{b}$ \\
\hline $\mathrm{CCl}_{4}$ & $111 \pm 16.16^{a}$ & $297 \pm 54.29^{a}$ \\
\hline $\begin{array}{c}\mathrm{CCl}_{4}+(\text { GLCsHPs }) \text { fraction } \\
(7.5 \mathrm{mg} / \mathrm{kg})\end{array}$ & $74.2 \pm 18.17^{a, b}$ & $212.1 \pm 36.39^{a, b}$ \\
\hline $\begin{array}{c}\mathrm{CCl}_{4}+(\text { GLCsHPs }) \text { fraction } \\
(15 \mathrm{mg} / \mathrm{kg})\end{array}$ & $70.4 \pm 23.15^{a, b}$ & $201.2 \pm 38.01^{a, b}$ \\
\hline $\begin{array}{c}\mathrm{CCl}_{4}+(\text { GLCsHPs }) \text { fraction } \\
(30 \mathrm{mg} / \mathrm{kg})\end{array}$ & $43.52 \pm 18.72^{b}$ & $144 \pm 26.7^{b}$ \\
\hline
\end{tabular}

* Data are the mean \pm SD (n=5-6). a or b: Significantly different from control or $\mathrm{CCl}_{4}$ group, respectively at $\mathrm{P}<0.05$ using ANOVA followed by Tukey-Kramer as a posthoc test. ALT: alanine aminotransferase ; AST: aspartate aminotransferase

\section{Histopathological findings}

Liver sections taken from the control group and stained with H\&E showed normal hepatic architecture where the hepatocytes showed a well-preserved cytoplasm and a well-defined nucleus (Fig.1A). However, the $\mathrm{CCl}_{4}$-intoxicated group showed extensive hepatocellular damage evidenced by the presence of centrolobular necrosis in diffuse manner all over the hepatocytes, ballooning degeneration, inflammatory infiltration of lymphocytes and fatty changes in most hepatic parenchyma (Fig.1 B\& C). Interestingly, the liver sections taken from the rats pretreated with different doses of the (GLCsHPs) fraction revealed that the fraction was able to reduce or even prevent the development of histopatholoogical damage particularly in the high dose $(30 \mathrm{mg} / \mathrm{kg})$ (Fig.1 D, E\&F). These observations supported the results obtained from serum 
enzymes assays, where a dose-dependent restoration of cellular integrity was confirmed.

A histopathologist graded these histopathological findings (Table 2).

Table 2. Histopathological grading.

\begin{tabular}{|c|c|c|c|}
\hline \multirow{2}{*}{ Groups } & \multicolumn{3}{|c|}{ Histopatholgical Grading } \\
\cline { 2 - 4 } & $\begin{array}{c}\text { Ballooning } \\
\text { Centrilobular } \\
\text { necrosis }\end{array}$ & $\begin{array}{c}\text { Fatty changes } \\
\text { degeneration with } \\
\text { inflammatory cells } \\
\text { in the } \\
\text { infiltration }\end{array}$ & $\begin{array}{c}\text { periphery of } \\
\text { lobules }\end{array}$ \\
\hline Control & - & - & - \\
\hline $\mathbf{C C l}_{4}$ & +++ & + & + \\
\hline $\mathbf{C C l}_{4}+(\mathbf{G L C s H P s})$ fraction \\
$(7.5 \mathrm{mg} / \mathrm{kg})$
\end{tabular}
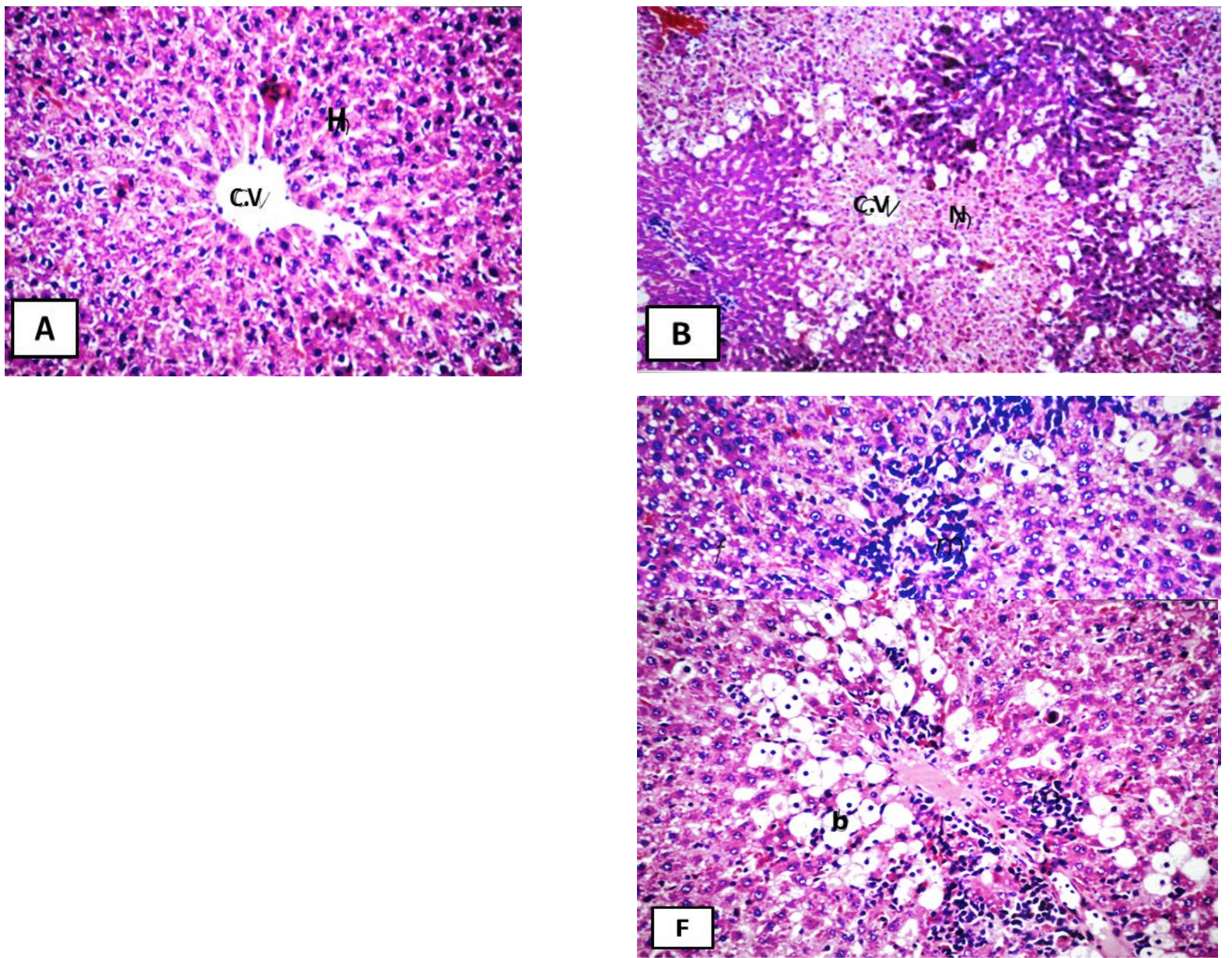


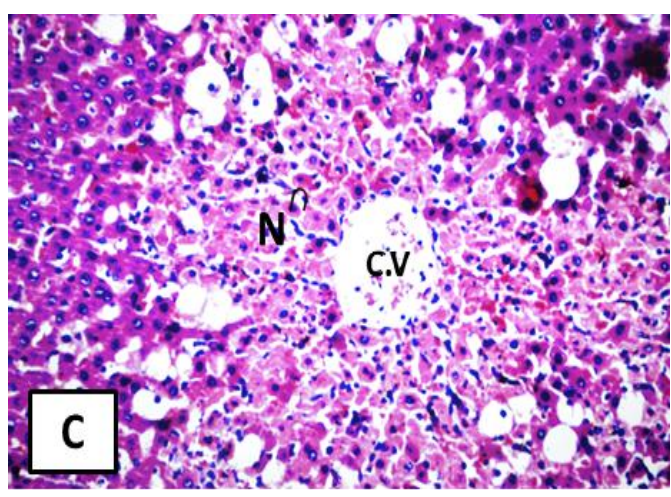

+++ (Severe), ++ (Moderate), +
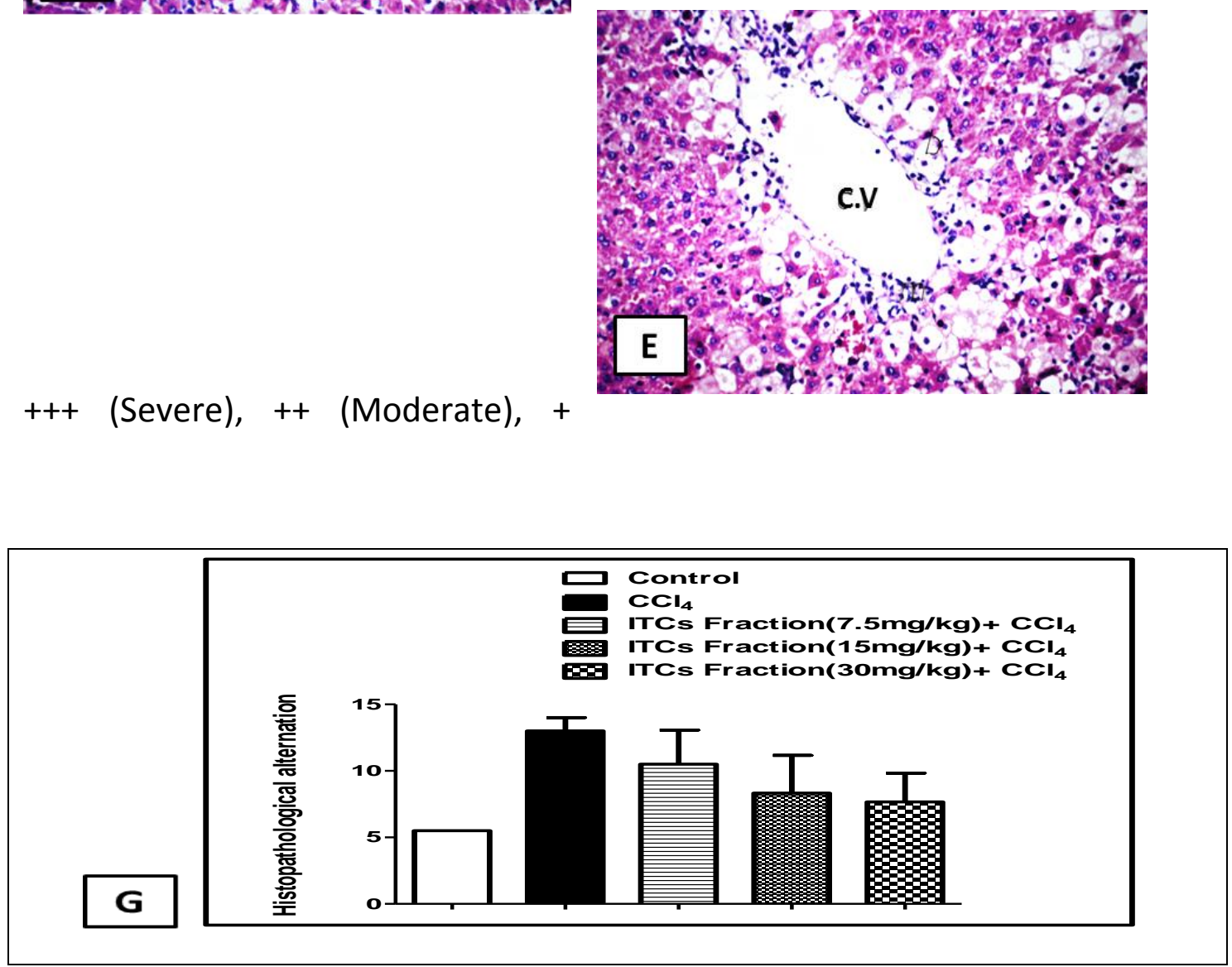

(Mild), - (Nil)

Fig. (1): Representative photomicrographs of liver sections stained by H \& E $(\times 40)$ of acute hepatotoxicity. A: section taken from a liver of control rat show normal hepatic archeticture, hepatocyte structure and central vein $(\mathrm{CV})$. B and C: Sections taken from liver of rats acute intoxicated with $\mathrm{CCl}_{4}$ show central vein $(\mathrm{CV})$, sever necrosis $(\mathrm{N})$, 
inflammatory infiltrate and ballooning. D, E and F: Sections taken from liver of rats treated with different doses of (GLCsHPs) fraction show ballooning (b) with fatty changes and inflammatory infiltrate in different degrees with absence of necrosis. G: Quantification of histopathological alternation. Values are given as mean \pm SD.

\section{DISCUSSION}

The present study was performed to assess the hepatoprotective activity of Matthiola arabica Boiss. in rats, against Carbon tetrachloride as hepatotoxin to prove the pharmacological effect of natural products against liver disorder. The changes associated with Carbon tetrachloride induced liver damage presented in form of excessive production of free radicals which cause lipid peroxidation of the hepatocellular membrane and followed by inflammatory cytokines release and, eventually, hepatocellular damage (Weber et al., 2003). The later was evidenced by the significant elevation in the serum levels of the aminotransferases enzymes ALT and AST levels as compared to the control group, because these enzymes release are associated with cellular damage (Recknagel et al., 1989). This biochemical elevation was confirmed with the histopathological sever necrosis, ballooning degeneration and heavy inflammatory infiltration in $\mathrm{CCl}_{4}$ treated animals.

The pre-treatment of animals with the (GLCsHPs) fraction at different doses $(7.5,15$ and $30 \mathrm{mg} / \mathrm{kg}$ ) have significantly reduced serum ALT and AST levels to an accepted extent. It was found that the third dose of $30 \mathrm{mg} / \mathrm{kg}$ is the most effective dose as it significantly reduced or even prevented the elevated liver enzymes to near control values. This confirmed with the pathohistological examination using H\& E staining for routine examination which showed absence of hepatocytes necrosis with the presence of mild ballooning and few inflammatory infiltration in cytoplasm. These findings are confirmed with the previously reported indirect antioxidant and anti-inflammatory effects of glucosinolates hydrolysis products (GLCsHPs) (Kong et al., 2010; Boddupalli et al., 2012).

\section{REFERENCES}

Al-Gendy,A.,A. and Lockwood,G.B. (2003). GC-MS of volatile hydrolysis products from glucosinolates in Farsetia aegyptia var.ovalis.Flav.Fragr. J., 18,148152.

Alqasoumi, S. (2010). Carbon tetrachloride-induced hepatotoxicity: protective effect of 'Rocket' Eruca sativa L. in rats. Am. J. Chin. Med., 38, 75-88.

Boddupalli,S.; Mein,R.,J.; Lakkanna,S. and James,R.,D. (2012). Induction of Phase 2 Antioxidant Enzymes by Broccoli Sulforaphane: Perspectives in Maintaining the Antioxidant Activity of Vitamins A, C, and E. Front Genet, 3, 7.

Boulos, L. (1999). Flora of Egypt. Vol. 1 (Azollaceae-Oxalidaceae), Al Hadara Publishing, Cairo, Egypt, 200-201.

Fahey, J.,W.; Zalcmann, A., T. and Talalay,P. (2001). The chemical diversity and distribution of glucosinolates and isothiocyanates among plants. Phytochem. J, 56(1), 5-51. 
Fenwick, G., R.; Heaney, R., K. and Mullin, W., J. (1983). Glucosinolates and their breakdown products in food and food plants. Crit. Rev. Food Sci. Nutr., 18(2), $123-201$.

Gil, V. and MacLeod, A. (1980). Benzylglucosinolate degradation in Lepidium sativum: Effect of plant age and time of autolysis. Phytochem. J., 19(7), 13651368.

Guicciardi, M.E. and Gores, G.J. (2005). Apoptosis: a mechanism of acute and chronic liver injury. Gut, 54, 1024-1033.

Kong,JS.; Yoo,SA.; Kim,HS.; Kim,HA.; Yea,K.; Ryu,SH.; Chung,YJ.; Cho,CS. and Kim,WU. (2010). Inhibition of synovial hyperplasia, rheumatoid $T$ cell activation, and experimental arthritis in mice by sulforaphane, a naturally occurring isothiocyanate. Arthritis Rheum., 62(1), 159-170.

Loguercio, C. and Federico, A. (2003). Oxidative stress in viral and alcoholic hepatitis. Free Radic. Biol. Med., 34, 1-10.

Martini, F.H. ; Timmons,M.J. and Tallitsch, R.B. (2006). Human anatomy ( $5^{\text {th }}$ ed.). Benjamin Cummings, San Francisco.

Matkowski, A. (2008). Plant in vitro culture for the production of antioxidants - a review. Biotechnol. Adv., 26, 548-560.

Recknagel, R.O., Glende, E.A., Jr., Dolak, J.A., Waller, R.L., (1989): Mechanisms of carbon tetrachloride toxicity. Pharmacol Ther 43, 139-154.

Sargent, S. (2009). Liver diseases: An essential Guide for Nurses and Health Care Professionals, $\left(1^{\text {st }}\right.$ ed.) Wliey- Blackwell.

Täckholm, V. (1974). Student's Flora of Egypt. Cairo University, Cairo, 180.

Vaughn, S., F. (1999). Glucosinolates as natural pesticides. In H. G. Cutler \& S. J. Cutler (Eds.), Principles and practices in plant allelochemical interactions (81-91).Boca Raton, FL: CRC Press.

Weber, L.W., Boll, M., Stampfl, A., (2003): Hepatotoxicity and mechanism of action of haloalkanes: carbon tetrachloride as a toxicological model. Crit Rev Toxicol $33,105-136$. 


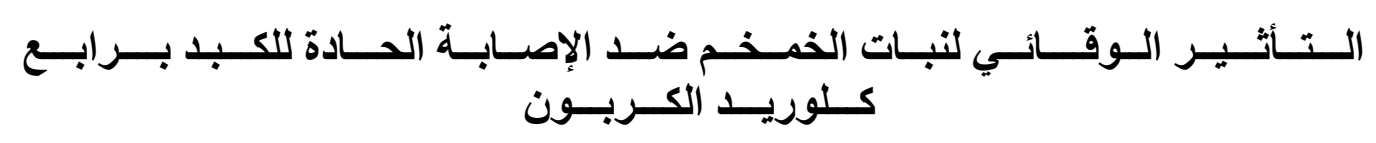

للسادة الاكاتزة

$$
\begin{aligned}
& \text { إيمان دسوقي محمد ' ، دريم نبيل أبو النجاب، رحاب أحمد لطفي '، إبتهال الدمرداش ب } \\
& \text { م- مســن } \\
& \text { أ: وحدة المنتجات الطبيعية، قسم النباتات الطبية و العطرية، مركز بحوث الصحر اء } \\
& \text { ب: قسم الأدوية و السموم، كلية الصيدلة، جامعة عين شمس }
\end{aligned}
$$

تعتبر أمر اض الكبد المزمنة واحدة من أكثر الأسباب شيوعا المؤدية للموت في العالم لعدة أسباب مختلفة.

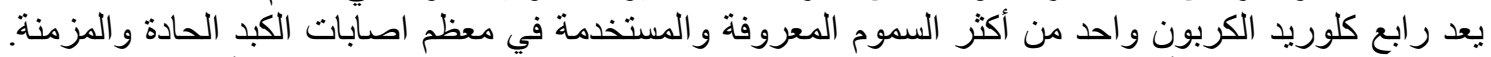

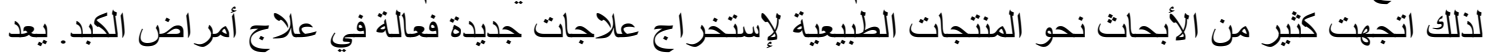

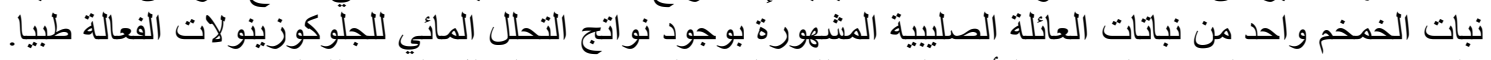

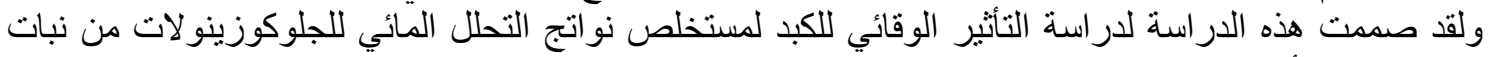

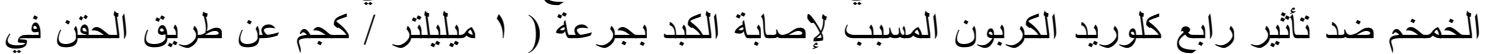

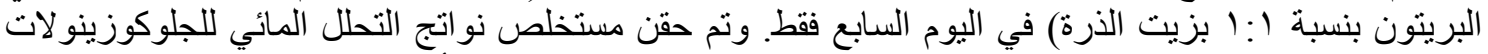

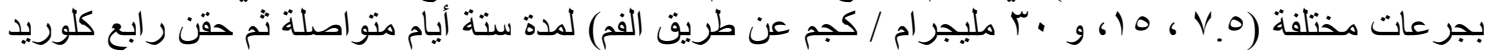

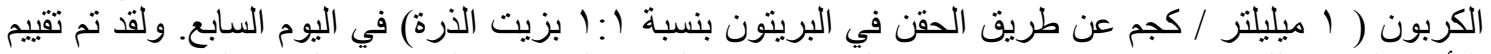

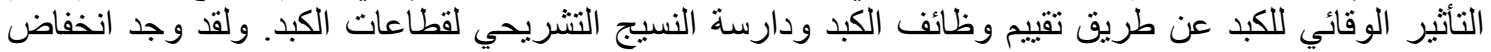

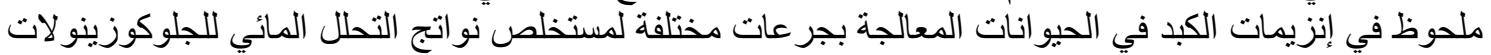

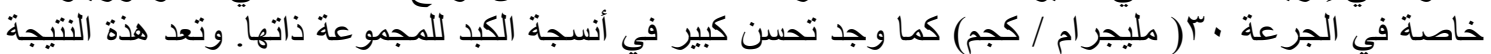

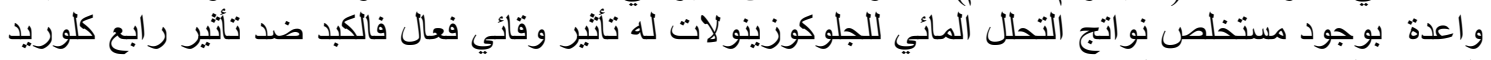
الكربون المسبب لإصدابة الكبد. 